\title{
Influence of the Thyroid State on the Intrinsic Contractile Properties and Energy Stores of the Myocardium*
}

\author{
Robert A. Buccino, James F. Spann, Jr., Peter E. Pool, Edmund H. \\ SONNENBLICK, AND Eugene BRAunWALd \\ (From the Cardiology Branch, National Heart Institute, Bethesda, Maryland)
}

\begin{abstract}
The intrinsic contractile properties of isolated cat papillary muscles and myocardial high energy phosphate stores were examined at three levels of thyroid activity and correlated with hemodynamic measurements in the intact animal. In addition, the relationship of thyroid state to endogenous norepinephrine stores and myocardial responsiveness to certain inotropic interventions were studied. In muscles from hyperthyroid cats, the velocity of shortening and the rate of tension development were markedly augmented, while duration of active state was decreased, compared to euthyroid muscles. These findings occurred in the presence and absence of intact norepinephrine stores and over a wide range of temperature and contraction frequency. The opposite changes occurred in muscles from hypothyroid cats. Isometric tension was slightly higher in muscles from hyperthyroid and lower in muscles from hypothyroid cats. The inotropic response to both norepinephrine and strophanthidin varied inversely with the level of thyroid state and allowed all three groups of muscles to reach a common ceiling of isometric tension regardless of thyroid state. Creatine phosphate and adenosine triphosphate stores were intact at all three levels of thyroid state. Thus, the level of thyroid activity profoundly affects the intrinsic contractile state of cardiac muscle, independent of both norepinephrine stores and alterations in high energy phosphate stores, and, in addition, modifies the responsiveness of cardiac muscle to inotropic agents.
\end{abstract}

\section{Introduction}

It is well known that alterations in thyroid activity result in profound changes in cardiovascular function. It has been shown, or it is generally believed, that cardiac index, heart rate, mean systolic ejection rate, and the response to sympathetic stimuli are elevated in hyperthyroidism, while peripheral vascular resistance, arterio-mixed venous $\mathrm{O}_{2}$ difference, and the response to digitalis glycosides are reduced (1-5). The opposite changes have been noted in myxedema. In the intact organism, these alterations ir cardiovascular function have been interpreted as secondary

* Received for publication 29 March 1967 and in revised form 9 June 1967.

Address requests for reprints to Dr. Engene Braunwald, Cardiology Branch, National Heart Institute, Bethesda, Md. 20014. to the changes in peripheral metabolic requirements $(1,2)$, in peripheral vascular resistance $(3)$, and in the autonomic nervous system $(2,6)$ induced by the abnormal thyroid state. However, the possibility exists that thyroid hormone exerts a more direct effect on the intrinsic contractile properties of the myocardium and that the changes in the circulation result, at least in part, from such a direct effect. Furthermore, assessment of myocardial energy stores is essential in relation to studies of contractility, since considerable evidence has accumulated to indicate an effect of thyroid hormone on oxidative phosphorylation (7).

Accordingly, the aim of the present investigation was to determine the effects of hyper- and hypothyroidism on: (a) the intrinsic contractile properties of the myocardium in the presence and 
absence of intact norepinephrine stores; $(b)$ the contractile responses of the myocardium to various inotropic stimuli; and (c) the high energy phosphate stores in the myocardium. The recent development of methods for detailed and quantitative analysis of mechanical characteristics of isolated cat papillary muscle (8), removed from the nervous, humoral, and metabolic influences that exist in vivo, and the ability to compare the function of muscles obtained from different groups of animals (9), permit critical examination of these problems. In addition, although interpretation of many previous studies of myocardial high energy phosphate stores in altered thyroid states (10-14) was limited by the extreme lability of these energy stores, recent modifications of biopsy and analytic techniques have made possible the accurate assessment of these stores in vivo (15, 16).

The basic experimental plan was to compare the behavior of muscles obtained from three groups of cats: ( $a$ ) untreated, i.e., euthyroid; $(b)$ hypothyroid; and $(c)$ hyperthyroid. Two additional groups of animals were studied to define the relationship between norepinephrine stores and hyperthyroidism; one group was subjected to catecholamine depletion with reserpine, administered before and concurrent with induction of the hyperthyroid state, and the other was treated with the same schedule of reserpine alone. The intrinsic contractile properties of isolated heart muscle were examined in papillary muscles and the effects of certain inotropic interventions were studied. To correlate the intrinsic function of the isolated myocardium with cardiovascular function in the intact organism, we performed cardiac catheterization and hemodynamic studies.

The results of these studies indicate that the intrinsic contractile state of cardiac muscle and its responsiveness to inotropic agents are profoundly affected by the level of thyroid state. Also it was found that these changes do not result from alterations in myocardial high energy phosphate stores and are not dependent upon intact norepinephrine stores.

\section{Methods}

Right ventricular papillary muscles were isolated from 24 normal cats, 13 cats given a single intraperitoneal injection of radioactive ${ }^{131} \mathrm{I}(1 \mathrm{mc} / \mathrm{kg}) 3$ months previously, 13 cats subjected to intraperitoneal injection of $l$-thyrox- ine ( $1 \mathrm{mg} / \mathrm{kg}$ per day) for $8-17$ days, six cats pretreated with reserpine $(0.5 \mathrm{mg} / \mathrm{kg}$ per day $)$ for 2 days and then treated concurrently with maintenance reserpine $(0.02 \mathrm{mg} / \mathrm{kg}$ per day) and $l$-thyroxine $(1 \mathrm{mg} / \mathrm{kg}$ per day) for an additional 8-13 days, and six cats treated only with reserpine in the same amounts. Before sacrifice, serum was obtained for determination of proteinbound iodine and cholesterol and right heart catheterization was performed. The animals were anesthetized with intravenous pentobarbital ( $10-25 \mathrm{mg} / \mathrm{kg})$; arterial pressure and blood samples were obtained through a polyethylene catheter inserted into the abdominal aorta via the femoral artery, while right ventricular pressure and mixed venous blood were obtained through a catheter inserted into the right ventricle from the external jugular vein. The electrocardiogram was monitored, pressures were measured by Statham pressure transducers $(\mathrm{P} 23 \mathrm{Db}$, Statham Instruments, Inc., Los Angeles, Calif.), and all signals were recorded on a multichannel oscillograph. Cardiac output was determined by the indicator dilution technique, with the injection of indocyanine dye into the right ventricle and the withdrawal of blood through a cuvette densitometer from the aorta. Oxygen consumption was calculated as the product of the cardiac output and the arterio-mixed venous oxygen difference and corrected for unit surface area according to the equation developed for the cat by Bartorelli and Gerola, $\mathrm{m}^{2}=$ $0.087 \mathrm{~kg}^{2 / 3}$ (17).

After the hemodynamics study, intermittent positive pressure ventilation was provided via a tracheostomy and care was taken to assure adequate oxygenation and a stable hemodynamic state. The chest was opened widely and biopsies of right and left ventricular myocardium for measurement of high energy phosphate stores were obtained with a 6 inch mastoid rongeur. Myocardial specimens, weighing an average of $22 \mathrm{mg}$, were frozen in liquid nitrogen within $0.5 \mathrm{sec}$. The sample from the second ventricle to be biopsied was analyzed only if obtained within 3 sec of the first biopsy. Biopsies were transventricular and the right ventricle was sampled first in most cases.

After the biopsies, the hearts were rapidly extirpated and right ventricular papillary muscles were removed immediately and suspended in a bath containing oxygenated Krebs' solution. The technique and apparatus utilized to study mechanical function of isolated papillary muscles have been described in detail (8). In brief, the papillary muscle was held at its lower nontendinous end by a springloaded clip, forming the end of a rigid pin penetrating the bottom of a bath and attached directly to a Statham (GI4-250) force transducer. The tendinous end of the muscle was attached to a lever mounted on a rigid Palmer stand (D12, C. F. Palmer, Ltd., London, England), arranged so that both isotonic and isometric contractions could be studied. Papillary muscles were stimulated with square wave DC impulses of $9 \mathrm{msec}$ duration and a voltage $10-25 \%$ greater than threshold, delivered through field electrodes placed parallel to the long axis of the muscle. Shortening, tension, and the stimulus artifact were recorded at a paper speed of $100 \mathrm{~mm} / \mathrm{sec}$ on a mul- 
TABLE I

Hemodynamic and biochemical determinations at three levels of thyroid activity

\begin{tabular}{|c|c|c|c|c|c|c|c|c|}
\hline & PBI & Cholesterol & $\begin{array}{l}\text { Heart } \\
\text { rate }\end{array}$ & $\begin{array}{c}\text { Cardiac } \\
\text { index }\end{array}$ & Stroke index & $\begin{array}{l}\text { Mean } \\
\text { systolic } \\
\text { ejection } \\
\text { rate }\end{array}$ & $\begin{array}{c}\text { A-V O } \\
\text { difference }\end{array}$ & $\begin{array}{l}\text { Oxygen } \\
\text { consump- } \\
\text { tion }\end{array}$ \\
\hline & $\mu g / 100 \mathrm{ml}$ & $\mathrm{mg} / 100 \mathrm{ml}$ & beats/min & $\underset{\text { per } \mathrm{kg}}{\mathrm{ml} / \mathrm{min}}$ & $m l / k g$ per beat & $\begin{array}{l}\mathrm{ml} / \mathrm{kg} \\
\text { per sec }\end{array}$ & vol \% & $\underset{\text { per } m^{2}}{m l / m i n}$ \\
\hline Hypothyroid & $\begin{array}{c}1.2 \pm 0.2^{*} \\
(15)\end{array}$ & ${ }_{(15)}^{124.3 \pm 13.1 \ddagger}$ & $160 \underset{(9)}{ \pm} 9 \S$ & $113 \underset{(9)}{ \pm} 9 \ddagger$ & $0.78 \pm 0.10 \ddagger$ & $3.0 \underset{(5)}{ \pm} 0.4^{*}$ & $\begin{array}{c}4.9 \pm 0.2 \ddagger \\
(9)\end{array}$ & $91 \underset{(9)}{ \pm} 10 \ddagger$ \\
\hline Euthyroid & $\begin{array}{c}4.3 \pm 0.2 \\
(24)\end{array}$ & $\begin{array}{c}101.2 \pm 10.0 \\
(24)\end{array}$ & 212 ( & $124 \underset{(7)}{ \pm} 18$ & $0.63 \underset{(7)}{ \pm} 0.09$ & $5.2 \underset{(7)}{ \pm} 0.3$ & $5.6 \underset{(7)}{ \pm} 0.4$ & $115 \underset{(7)}{ \pm} 16$ \\
\hline Hyperthyroid & $\begin{array}{l}>25^{*} \\
(12)\end{array}$ & ${ }_{(12)}^{49.1 \pm 3^{*}}$ & $245 \underset{(5)}{ \pm} 5 \ddagger$ & $212 \underset{(5)}{ \pm} 28 \S$ & $0.81 \underset{(4)}{ \pm} 0.09 \ddagger$ & $9.8 \underset{(3)}{ \pm} 1.0^{*}$ & $6.9 \underset{(4)}{ \pm} 0.7 \ddagger$ & $222 \pm 2{ }_{(4)}^{2}$ \\
\hline
\end{tabular}

PBI, protein-bound iodine; $\mathrm{A}-\mathrm{V}$, arteriovenous.

Values represent mean \pm standard error of the mean with the number of animals for each determination indicated in parentheses.

* $P=<0.01$ when compared to euthyroid.

$\ddagger P=>0.05$ when compared to euthyroid

$\S P=<0.05$ when compared to euthyroid.

tichannel oscillograph, and the rate of tension development, time to peak tension, and velocity of shortening were determined from these recordings. In order to

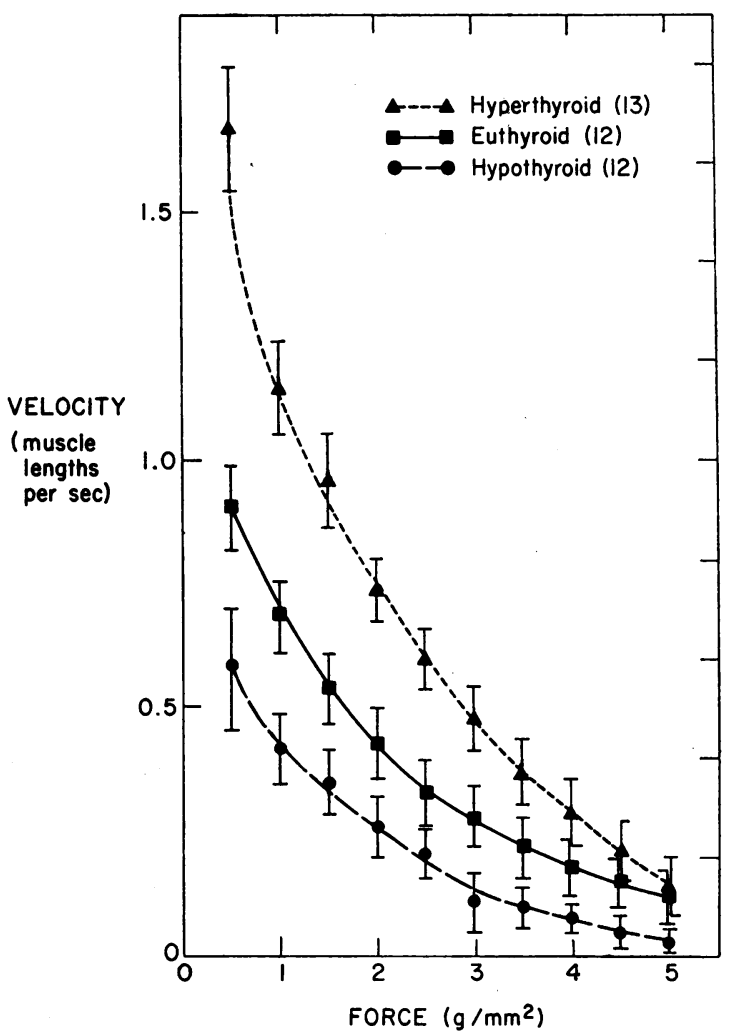

Fig. 1. THE AVERAGE FORCE-VELOCITY RELATIONSHIP FOR PAPILLARY MUSCLES FROM HYPERTHYROID, EUTHYROID, AND HYPOTHYROID CATS. Initial velocity of shortening is normalized in terms of muscle lengths per second, and load, corrected for cross-sectional area of individual muscles, is expressed in $\mathrm{g} / \mathrm{mm}^{2}$. Brackets represent \pm SEM. compare the mechanical function of papillary muscles of different sizes, we corrected tension for cross-sectional area and expressed it in grams per square millimeter and expressed velocity of shortening in terms of muscle lengths per second.

Temperature was maintained at $30^{\circ} \mathrm{C}$ and frequency of contraction at $12 / \mathrm{min}$, except when the effects of changes in these two variables were studied specifically. Responsiveness to cardiac glycosides was studied by measuring the maximum active tension $20 \mathrm{~min}$ after the addition of strophanthidin to individual preparations to achieve final concentrations of $0.01,0.10,0.25,0.50$, and $1.00 \mu \mathrm{g} / \mathrm{ml}$. In separate muscles, the responsiveness to $l$-norepinephrine was similarly studied at 5 -min intervals with concentrations of $10^{-10}$ to $10^{-6}$ mole/liter, without washout between additions of the catecholamine.

Right ventricular norepinephrine concentration was measured spectrophotofluorometrically by the trihydroxyindole method as described in detail elsewhere (18). Myocardial biopsies for high energy phosphate determinations were stored in liquid nitrogen. On the day of assay, each tissue was pulverized at $-50^{\circ} \mathrm{C}$ as previously described (16) and perchloric acid extracts were prepared. Creatine phosphate (CP) and inorganic phosphate $\left(P_{1}\right)$ were determined by the phosphomolybdate method of Fiske and Subbarow (19) as modified by Furchgott and De Gubareff (15). Creatine concentrations were measured by the $\alpha$-napthol-diacetyl method of Ennor and Rosenberg $(20,21)$, and adenosine triphosphate (ATP) by a modification of the firefly luminescence method of Strehler and McElroy (22). Modifications of these procedures have been described previously in detail (16). To avoid possible errors involved in weighing small tissues in the frozen state, we calculated sample weights by the determination of creatine concentration in two separately obtained samples of the right ventricle and the creatine content of the biopsy sample as previously described (16).

Statistical analyses were performed utilizing Student's unpaired $t$ test to compare the mean values in muscles 
from hyperthyroid and hypothyroid cats with those of euthyroid cats. Differences between groups were considered to be statistically significant when $P<0.01$ and probably significant when $0.01<P<0.05$.

\section{Results}

\section{Characterization of thyroid state}

A. Protein-bound iodine and serum cholesterol. Serum protein-bound iodine was significantly elevated in the hyperthyroid and reduced in the hypothyroid cats; serum cholesterol was significantly reduced in the hyperthyroid cats and slightly, but not significantly, elevated in the hypothyroid cats (Table I).

$B$. Hemodynamic measurements. In the hyperthyroid animals, cardiac index, mean systolic ejection rate, and total $\mathrm{O}_{2}$ consumption were all significantly elevated above normal while in the hy. pothyroid cats the heart rate and mean systolic ejection rate were reduced significantly below the values observed in the euthyroid animals (Table I).

\section{Myocardial mechanics}

A. Analysis of isotonic contractions. Maximum velocity of isotonic shortening $\left(V_{\max }\right)$ was found to vary directly with the level of the thyroid state (Fig. 1); at the lightest load studied $\left(0.5 \mathrm{~g} / \mathrm{mm}^{2}\right)$, $V_{\max }$ averaged $0.90 \pm 0.08$ muscle lengths/sec in the muscles from 12 euthyroid cats and was significantly lower $(P<0.01)$ in the muscles obtained from 12 hypothyroid cats $(0.58 \pm 0.12$ muscle lengths/sec) and significantly higher $(P<$ 0.01 ) in the muscles from 13 hyperthyroid cats $(1.67 \pm 0.12$ muscle lengths $/ \mathrm{sec})$. Expressed in terms of Hill's equation (23), these curves can be analyzed as displaced hyperbolae (24) and the constants $a$ and $b$ and the actual $V_{\max }$ of the Hill equation may be calculated (Fig. 2). The ratio $a / P_{o}$, which characterizes the steepness of the force-velocity curve, was not greatly altered by changes in thyroid state, while $b$, the velocity constant, and calculated $V_{\max }$ which equals $\left(P_{o} / a\right) b$, were directly related to the level of thyroid activity.

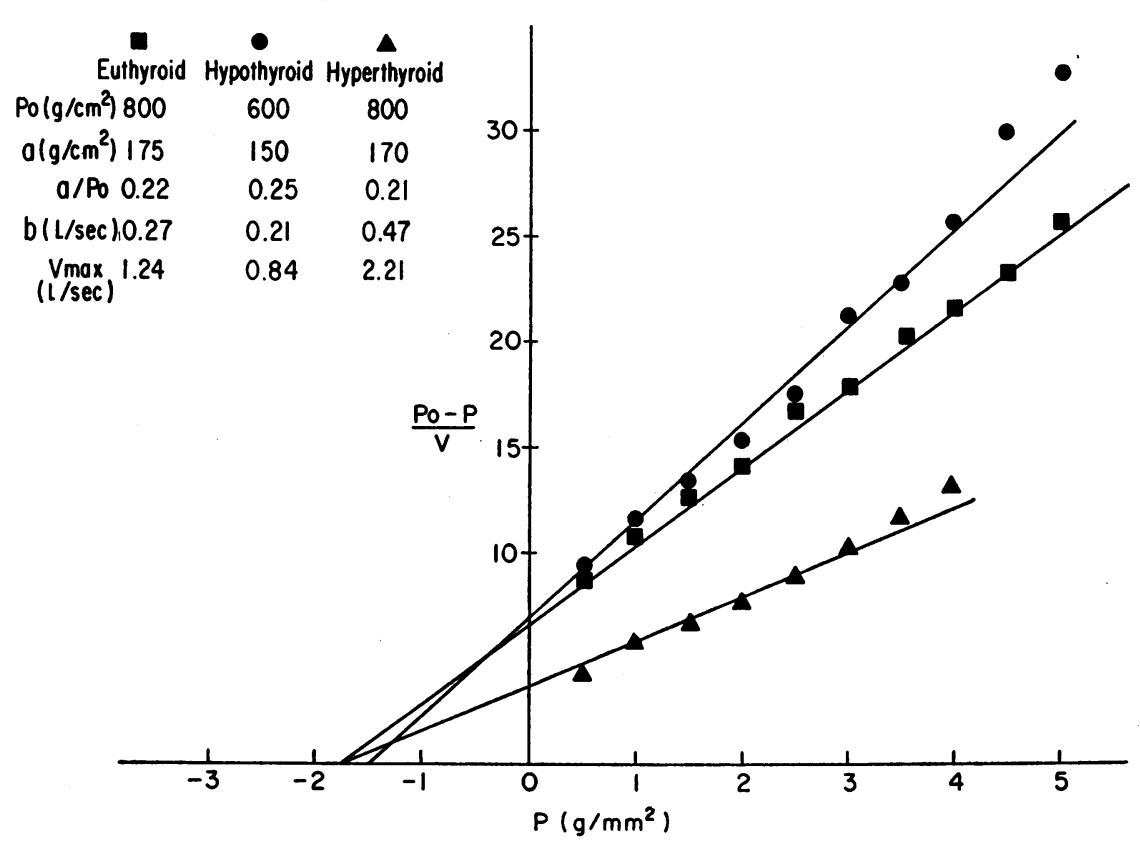

Fig. 2. Constants of the Hill equation obtained by linearization of the DATA shown IN Fig. 1. The Hill equation, $(P+a) V=\left(P_{0}-P\right) b$, may be rearranged to the form of a linear equation, $P_{\bullet}-P / V=1 / b(P+a)$, where $P=$ load, $V=$ velocity of shortening, $P_{0}=$ maximum isometric force, and $a$ and $b$ are constants which may be derived from the force-velocity curve. Substituting the values from Fig. 1, the relations shown in Fig. 2 are obtained. The slope of the line equals $1 / b$, and the intercept on the $y$ axis equals $a$ in the Hill equation. The values thus obtained are shown in the insert of the figure. 


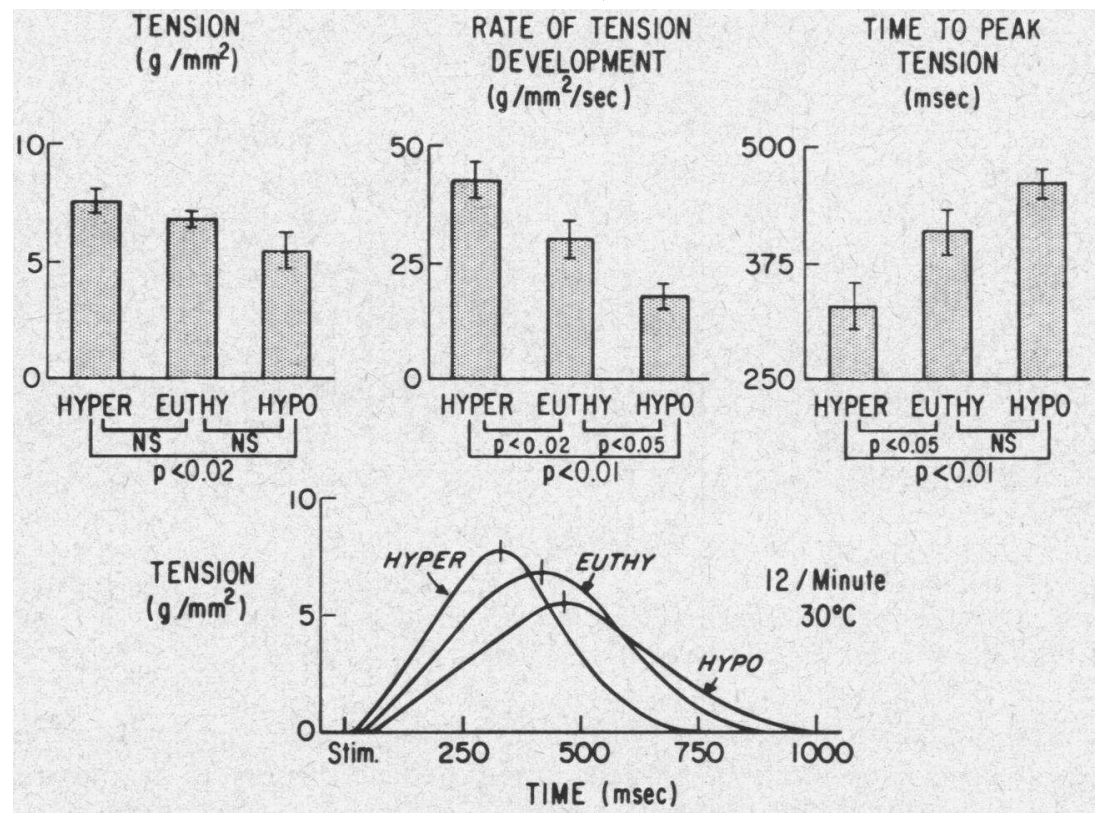

Fig. 3. ISOMETRIC TENSION EXAMINED IN RELATION TO TIME AND ANALYZED IN TERMS OF ITS COMPONENT FACTORS AS A FUNCTION OF LEVEL OF THYROID STATE. Tension represents maximum active tension, measured at the peak of the lengthactive tension curve. Rate of tension development was measured as the maximum slope of the tension curve, and time to peak tension was measured from the stimulus. Tension curves in the lower panel represent average data, as presented in columns of the upper panel, for muscles from 11 hyperthyroid, 8 euthyroid, and 13 hypothyroid cats. NS $=P>0.05$.

B. Analysis of isometric contractions. The compliance of the papillary muscle was unchanged by alterations in the level of thyroid state as shown by the essentially identical length-resting tension curves in the muscles from all three groups of cats. At $L_{\max }$, i.e. the muscle length at which active tension was maximal, resting tension averaged $1.9 \pm$ $0.6 \mathrm{~g} / \mathrm{mm}^{2}$ in the muscles obtained from the 7 hyperthyroid cats, $2.3 \pm 0.4 \mathrm{~g} / \mathrm{mm}^{2}$ in the muscles obtained from the 12 euthyroid cats, and $2.5 \pm 0.3$ $\mathrm{g} / \mathrm{mm}^{2}$ in the muscles obtained from the 11 hypothyroid cats. These values did not differ significantly from one another nor were there differences in resting tension among the three groups of muscles at other portions of the length-resting tension curve.

Active tension at the peak of the length-active tension curve averaged $6.8 \pm 0.3 \mathrm{~g} / \mathrm{mm}^{2}$ in the muscles from 24 euthyroid animals, $7.7 \pm 0.5 \mathrm{~g} /$ $\mathrm{mm}^{2}$ in the muscles from 11 hyperthyroid animals, and $5.4 \pm 0.7 \mathrm{~g} / \mathrm{mm}^{2}$ in the muscles from $13 \mathrm{hy}$ pothyroid animals. Although the hyper- and hypothyroid groups did not differ significantly from the euthyroid, the maximum isometric tension in the hyperthyroid muscles was significantly $(P<$ 0.02 ) greater than that in the hypothyroid group. When tension was explained as a function of time and analyzed in terms of the rate of tension development and the time from stimulus to peak tension, it was observed that the level of thyroid state affects the contractile performance of the isometrically contracting muscle to a much greater extent than is indicated by the relatively small changes in peak tension (Fig. 3). Time to peak tension varied inversely with the level of thyroid state, averaging $458 \pm 16,406 \pm 22$, and $326 \pm 28$ msec, and the rate of tension development varied directly, averaging $17.6 \pm 2.8,29.8 \pm 3.9$, and $44.6 \pm 3.6 \mathrm{~g} / \mathrm{mm}^{2}$ per $\mathrm{sec}$, for the hypothyroid, euthyroid, and hyperthyroid groups, respectively, measured at $30^{\circ} \mathrm{C}$ and 12 contractions/min.

Variations in temperature from $21^{\circ}$ to $37^{\circ} \mathrm{C}$ and variations in the frequency of contraction from 6 to $48 / \mathrm{min}$ resulted in directionally similar changes in the time to peak tension and the rate of tension development in muscles from each group of ani- 

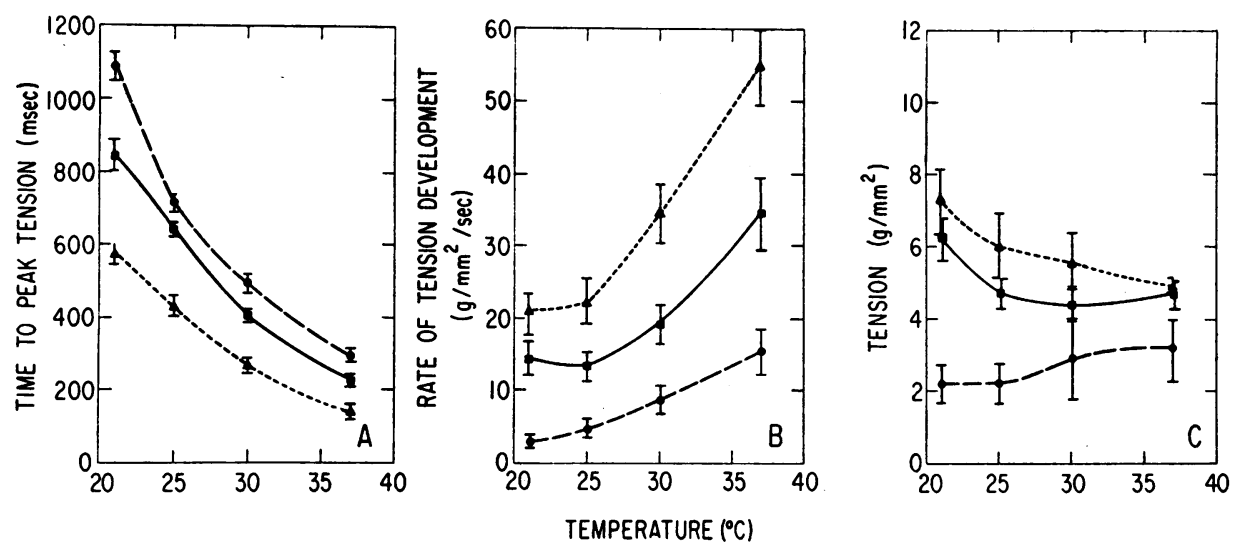

Fig. 4. Time to peak tension (A), rate of tension development (B), and tension (C) MEASURED AT VARIOUS TEMPERATURES IN 8 MUSCLES FROM HYPERTHYROID CATS $(\boldsymbol{\Delta}), 10$ FROM EUTHYROID CATS ( $\boldsymbol{\square})$, AND 5 FROM HYPOTHYROID CATS $(\bullet)$.

mals (Figs. 4 and 5). Consequently, the differences in time to peak tension and rate of tension development observed at $30^{\circ} \mathrm{C}$ and 12 contractions/min among the three groups pertained to the entire range of temperature and frequency studied.

Absolute tension represents the interaction between the rate of tension development and the time to peak tension. As temperature was raised in muscles obtained from hyperthyroid and euthyroid cats, at a constant frequency $(12 / \mathrm{min})$, time to peak tension was shortened relatively more than the rate of tension development was augmented, so that tension fell (Fig. 4C). On the other hand, in muscles removed from hypothyroid cats, the reciprocal changes in the rate of tension development and time to peak tension were of similar relative magnitude, so that the resultant tension showed little change as temperature was varied between $21^{\circ}$ and $37^{\circ} \mathrm{C}$. When temperature was maintained constant (at $30^{\circ} \mathrm{C}$ ) and frequency of contraction increased from 6 to $48 / \mathrm{min}$, the time to peak tension declined (Fig. 5A) while the rate of tension development was augmented in all three groups of muscles (Fig. 5B). In the muscles removed from the euthyroid and hypothyroid cats, the rate of tension development rose proportionately more than the time to peak tension declined and, as a consequence, tension increased as frequency was elevated. On the other hand, in the muscles removed from hyperthyroid cats, the augmentation in the rate of tension development was not as great as in the
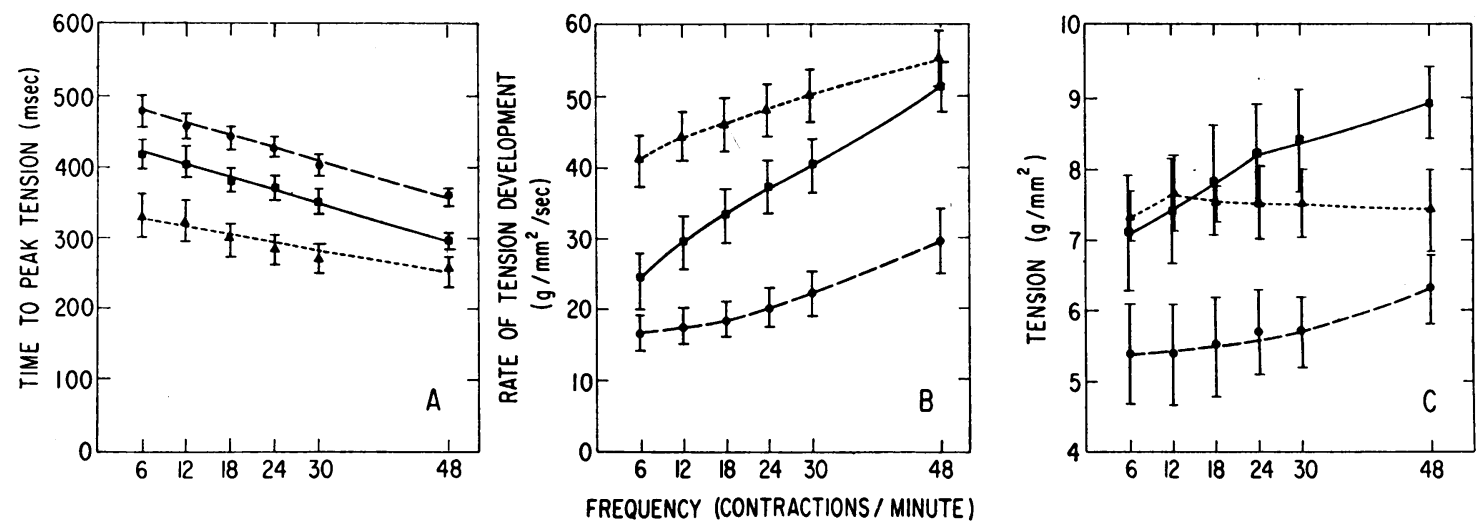

Fig. 5. Time to peak tension (A), rate of tension development (B), and tension (C) measured at variOUS CONTRACTION FREQUENCIES IN MUSCLES FROM 11 HYPERTHYROID CATS ( $\mathbf{\Delta}$ ), 8 EUTHYROID CATS ( $\boldsymbol{\square}$ ), AND 12 HYPOTHYROID CATS ( $\bullet$ ). 

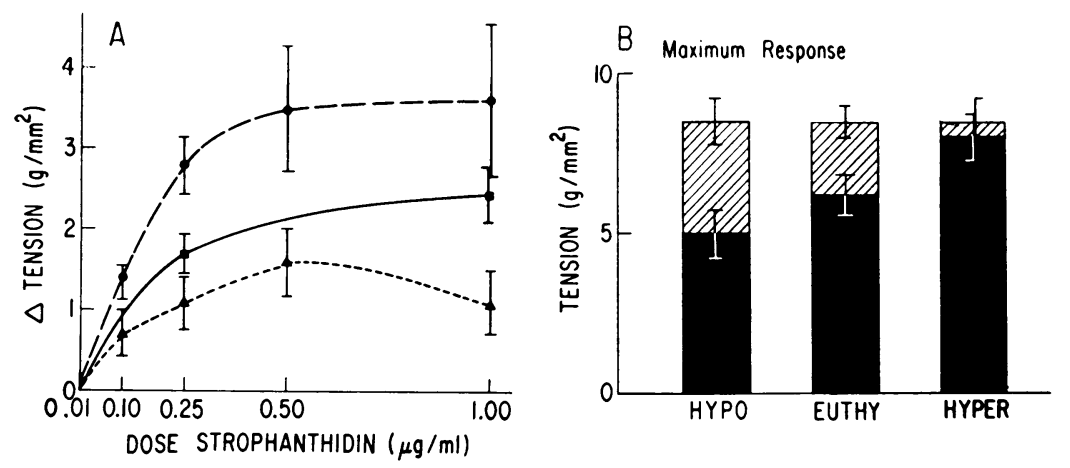

Fig. 6. The efFects of a Cardiac glycoside, strophanthinix, ox isometric TENSION AT $30^{\circ} \mathrm{C}$ AND 12 CONTRACTIONS/MIN IN PAPILLARY MICSCLES FROM 7 HYPERTHYROID CATS ( $), 12$ ELTHYROID CATS ( $)$, AND 8 HYPOTHYROID CATS ( ) . The average increment in tension is plotted as a function of strophanthidin concentration (A) and the maximum response is shown with respect to initial tension (B) for each group of muscles. Initial tension, indicated by the solid columns, represents the control before addition of strophanthidin. Maximum response, indicated by the broken portion of each column, represents the average of the maximum increment in tension produced by strophanthidin in each muscle.

other two groups and thus no change in tension occurred (Fig. 5C).

\section{Responsiz'ness to cardiuc glycosides}

As shown in Fig. 6A, muscles obtained from hyperthyroid cats exhibited a smaller contractile response and those from hypothyroid cats a greater response than muscles from euthyroid cats. With the largest concentration of strophanthidin $(1 \mu \mathrm{g} /$ m1), the increments in tension averaged $1.1 \pm 0.4$ $\mathrm{g} / \mathrm{mm}^{2}$ for the hyperthyroid muscles, a value significantly $(I<0.05)$ lower than $2.5 \pm 0.3 \mathrm{~g} / \mathrm{mm}^{2}$ in the euthyroid muscles, and $3.6 \pm 1.0 \mathrm{~g} / \mathrm{mm}^{2}$ in
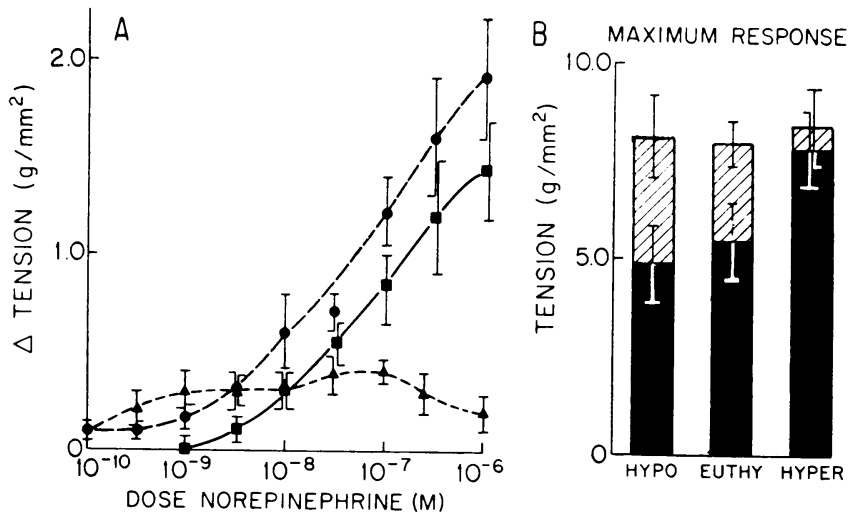

Fig. 7. THE fFFects of Exogexols NOREPLAPHRINE ON ISOMETRIC TENSION AT $30^{\circ} \mathrm{C}$ AND 12 CONTRACTIONS/MIN IN PAPILLARY MLSCLES FRON 7 HYPERTHYROID CATS $(\boldsymbol{\Delta}), 8$ FUTHYROID CATS ( $\mathbf{a}$ ), AND 10 HYPOTHYRoIn cats ( $)$. The average increment in tension is plotted as a function of norepinephrine concentration (A) and the maximum response is shown with respect to initial tension (B) for each group of muscles. Initial tension, indicated by the solid columns, represents the control before addition of norepinephrine. Maximum response, indicated by the broken portion of each column, represents the average of the maximum increment in tension produced by norepinephrine in each muscle. 


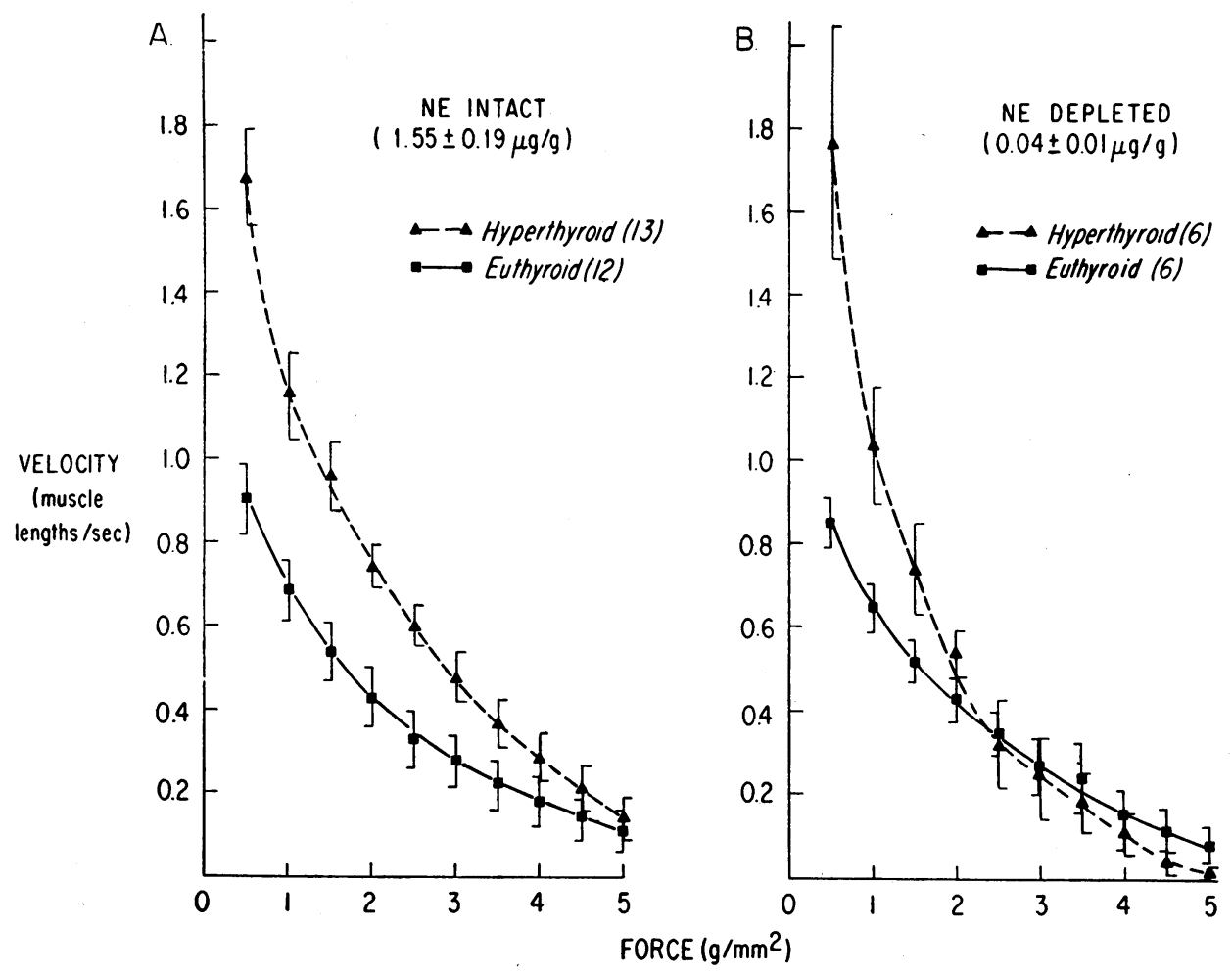

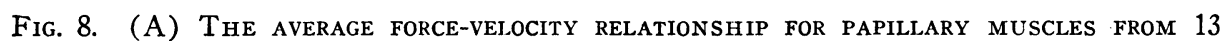
HYPERTHYROID AND 12 EUTHYROID CATS WITH INTACT CARDIAC NOREPINEPHRINE STORES. Right ventricular norepinephrine $(N E)$ concentration is indicated in parentheses.

(B) The average force-velocity relat onship for papillary muscles from six hyperthyroid and six euthyroid cats depleted of norepinephrine by reserpine. Right ventricular norepinephrine concentration is indicated in parentheses.

the hypothyroid muscles. The magnitude of the increase in force produced by strophanthidin varied inversely with the control maximum isometric tension, in such a way that the absolute levels of tension after strophanthidin were nearly identical in all three groups of muscles, averaging $8.5 \pm 0.5$ $\mathrm{g} / \mathrm{mm}^{2}$ in the hypothyroid group, $8.4 \pm 0.5 \mathrm{~g} / \mathrm{mm}^{2}$. in the euthyroid group, and $8.6 \pm 0.8 \mathrm{~g} / \mathrm{mm}^{2}$ in the hyperthyroid group (Fig. 6B).

\section{Relationship between sympathetic neurotrans- mitter stores and cardiac muscle function}

A. Responsiveness to norepinephrine. Muscles obtained from hyperthyroid cats were not supersensitive to norepinephrine when it was added to the bath and in fact responded far less than euthyroid muscles. Although muscles obtained from hypothyroid animals appeared to respond to a greater extent than euthyroid muscles, this difference was not significant. At a concentration of
$10^{-6} \mathrm{M}$ norepinephrine, the increment in maximum active tension averaged $0.2 \pm 0.1,1.4 \pm 0.3$, and $1.9 \pm 0.3 \mathrm{~g} / \mathrm{mm}^{2}$, for hyperthyroid, euthyroid, and hypothyroid groups, respectively (Fig. 7A). As was noted in the case of strophanthidin, the increment in tension was inversely related to the level of tension before the addition of the norepinephrine and the absolute levels of tension after norepinephrine were similar in all three groups of muscles (Fig. 7B).

$B$. Right ventricular norepinephrine concentration. Right ventricular norepinephrine concentration averaged $1.55 \pm 0.19,2.13 \pm 0.30$, and 1.82 $\pm 0.15 \mu \mathrm{g} / \mathrm{g}$ in the ventricles obtained from the hyperthyroid, euthyroid, and hypothyroid groups respectively; these values did not differ significantly from one another. Norepinephrine stores were essentially eliminated in the six animals treated with reserpine before and during induction of the hyperthyroid state and averaged $0.04 \pm 0.01 \mu \mathrm{g} / \mathrm{g}$. 
C. Myocardial mechanics. The increase in the velocity of shortening observed in muscles from hyperthyroid cats with normal norepinephrine stores (Fig. 8A) was also seen in muscles from animals depleted of norepinephrine by pretreatment with reserpine (Fig. $8 \mathrm{~B}$ ); at a load of 0.5 $\mathrm{g} / \mathrm{mm}^{2}, V_{\max }$ averaged $0.85 \pm 0.06$ muscle lengths/ $\mathrm{sec}$ in muscles from six animals given reserpine alone and was significantly greater $(P<0.01)$, $1.76 \pm 0.27$ muscle lengths/sec, in the muscles from reserpine-treated hyperthyroid animals. The latter value was essentially identical with that observed in the noncatecholamine depleted muscles from hyperthyroid animals, $1.67 \pm 0.12$ muscle lengths/sec. Reduction of the time to peak tension and augmentation of the rate of tension development similar to that observed in muscles from hyperthyroid animals occurred in the muscles from cats pretreated and maintained on reserpine concomitant with thyroxine. Thus, time to peak tension averaged $245 \pm 17 \mathrm{msec}$ in muscles obtained from the reserpine-thyroxine-treated group, compared to $496 \pm 18 \mathrm{msec}$ in muscles obtained from reserpine-treated euthyroid animals $(P<0.01)$, while the rate of tension development averaged $32.6 \pm 2.5 \mathrm{~g} / \mathrm{mm}^{2}$ per sec in the reserpine-thyroxine-treated group compared to $23.2 \pm 3.5 \mathrm{~g} /$ $\mathrm{mm}^{2}$ per sec in the reserpine-treated controls $(P<0.05)$.

\section{$V$. Myocardial energy stores}

Myocardial creatine phosphate concentrations did not differ significantly in either ventricle among the hyperthyroid, euthyroid, and hypothyroid groups (Table II). ATP concentrations tended to be higher in hyperthyroid and lower in hypothyroid than in euthyroid animals; this difference was significant $(P<0.05)$ with respect to the right ventricle only in hyperthyroid cats and with respect to the left ventricle only in hypothyroid cats. In both ventricles, however, ATP concentrations were slightly, though significantly higher $(P<0.05)$ in hyperthyroid as compared to hypothyroid animals.

The total high energy phosphate stores, i.e. the sum of creatine phosphate and ATP, were virtually identical in both ventricles in all three groups of cats. Inorganic phosphate concentrations were significantly lower in hypothyroid than in hyperthyroid cats $(P<0.01)$ in both ventricles, while creatine stores were significantly lower in both hyperthyroid and hypothyroid cats when compared to the euthyroid group in both ventricles $(P<0.02)$.

\section{Discussion}

The major finding of this investigation is that the thyroid state profoundly affects the intrinsic

TABLE II

Myocardial energy stores

\begin{tabular}{|c|c|c|c|c|c|c|}
\hline & \multicolumn{3}{|c|}{ Right ventricle } & \multicolumn{3}{|c|}{ Left ventricle } \\
\hline & Нypo & Euthy & Hyper & Нyро & Euthy & Hyper \\
\hline \multirow[b]{2}{*}{$\mathrm{Cr}$} & & umoles $/ \mathrm{g}$ & & & 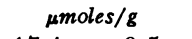 & \\
\hline & $12.0 \underset{(14)}{ \pm} 0.6^{*}$ & $15.5 \underset{(20)}{ \pm 0.6}$ & $12.8 \underset{(13)}{ \pm 0.4 \ddagger}$ & $14.2 \underset{(14)}{ \pm} 0.8^{*}$ & 17.4 (19) $^{ \pm} 0.5$ & $13.6 \underset{(13)}{ \pm 0.5^{*}}$ \\
\hline $\mathrm{CP}$ & $7.25 \underset{(8)}{ \pm} 0.90 \S$ & $\begin{array}{c}7.22 \pm 0.49 \\
(17)\end{array}$ & $6.13 \underset{(8)}{ \pm} 0.48 \S$ & $\begin{array}{c}7.35 \pm 0.67 \S \\
(11)\end{array}$ & $\begin{array}{l}7.85 \pm 0.68 \\
(12)\end{array}$ & $6.59 \pm 0.61 \S$ \\
\hline ATP & $4.83 \underset{(8)}{ \pm} 0.32 \S$ & $\begin{array}{c}5.13 \pm 0.22 \\
(17)\end{array}$ & $6.00 \underset{(8)}{ \pm} 0.41 \ddagger$ & $\begin{array}{l}4.84 \pm 0.27 \ddagger \\
(11)\end{array}$ & $\begin{array}{c}5.76 \pm 0.31 \\
(12)\end{array}$ & $\begin{array}{c}5.85 \pm 0.43 \S \\
(8)\end{array}$ \\
\hline $\mathrm{CP}+\mathrm{ATP}$ & $12.08 \pm 1.09 \S$ & ${ }_{(17)}^{12.35 \pm 0.52}$ & $12.13 \pm 0.31 \S$ & $\begin{array}{c}12.19 \pm 0.75 \S \\
(11)\end{array}$ & ${ }_{(12)}^{13.61 \pm} 0.71$ & $12.44 \underset{(8)}{ \pm} 0.80 \S$ \\
\hline$P_{i}$ & $3.76 \underset{(8)}{ \pm} 0.32 \S$ & $\begin{array}{c}4.10 \underset{(17)}{ \pm} 0.32 \\
0\end{array}$ & $5.78 \underset{(8)}{ \pm} 0.43 \ddagger$ & ${ }_{(11)}^{3.70 \pm 0.28^{*}}$ & $\begin{array}{l}5.32 \text { (12) } \\
0.38\end{array}$ & $5.12 \underset{(8)}{ \pm} 0.368$ \\
\hline
\end{tabular}

$\mathrm{Cr}$, creatine; $\mathrm{CP}$, creatine phosphate; ATP, adenosine triphosphate; $\mathrm{P}_{\mathrm{i}}$, inorganic phosphate.

Values represent mean \pm standard error of the mean with the number of animals for each determination indicated in parentheses.

${ }^{*} P=<0.01$ when compared to euthyroid.

$\ddagger P=<0.05$ when compared to euthyroid.

$\S P=>0.05$ when compared to euthyroid. 
contractile state of cardiac muscle, primarily by altering the speed of shortening of the contractile elements, as reflected by $V_{\max }$ in isotonic contractions and by the rate of tension development in isometric contractions. This observation suggests strongly that the abnormalities in cardiovascular dynamics observed in the intact organism with hyper- or hypothyroidism (Table I) (1-4) do not result merely from the changes in the load placed upon the heart by the induced alterations in the metabolism of extracardiac tissues; but rather, it indicates that the changes observed in cardiac index, mean systolic ejection rate, and myocardial fiber-shortening rate result, at least in part, from effects on the intrinsic contractile properties of the myocardium exerted by thyroid hormone or some substance elaborated by the intact organism in response to the altered thyroid state. Moreover, these findings suggest that the inotropic properties of the heart are adjusted in a manner appropriate to meet the simultaneously induced alterations in peripheral requirements. The increased intrinsic velocity of contraction of hyperthyroid muscle helps assure an elevated cardiac output in this condition, since it permits an augmented velocity of ejection at a time when heart rate is increased. As a consequence, stroke index is maintained at a normal level, or even increased, while heart rate is augmented, resulting in a marked elevation of cardiac index (Table I).

That the thyroid state exerts only a minor effect on myocardial force development follows from the observation that the time to peak tension and the rate of tension development are affected in opposite directions by variations of thyroid state, in such a manner that resultant tension is not greatly altered. Muscles from hyperthyroid cats develop tension at a more rapid rate but for a shorter period of time than euthyroid muscles; and, conversely, muscles from hypothyroid cats develop tension at a slower rate, but this tends to be compensated for by a prolonged period of contraction. Thus, hyperthyroidism increases the intensity of the active state of the myocardium, as measured by the shift in the force-velocity curve and by increases in the rate of tension development, but simultaneously shortens the duration of active state, as reflected by abbreviation of the time to peak tension (25). These findings suggest that the thyroid state affects the contractile state of cardiac muscle profoundly by varying the rate of interaction at contractile sites, while altering the extent of force development only to a minor degree. Consonant with this view is the finding that the constant $b$ from the Hill equation (23), which reflects the rate with which energy leaves the muscle, also varied directly with increasing level of thyroid activity (Fig. 2).

Although time to peak tension and the rate of tension development vary inversely as the thyroid state is altered, these two parameters can, under other conditions, be affected separately. For example, we have recently observed that papillary muscle obtained from cats with right ventricular hypertrophy and failure exhibit diminished rates of development of tension as do muscles from hypothyroid animals, but exhibit no prolongation of the duration of the contraction. Therefore, unlike muscles obtained from hypothyroid animals, muscles from cats with heart failure exhibit striking reductions in the absolute levels of tension development (26). Similarly, when serotonin is administered to the isolated cat papillary muscles, the rate of tension development is augmented, as it is in muscles from cats with hyperthyroidism, but, unlike hyperthyroidism, the duration of contraction is not altered by serotonin (27). Thus, for a given increment in the rate of tension development, serotonin produces a profound increase in tension whereas hyperthyroidism does not.

From these findings, it is apparent that when tension alone is measured, large changes in the contractile state of the myocardium can be overlooked. This fact may account, at least in part, for conflicting data reported in earlier studies of this problem. Studying hypothyroid rats, Benforado and Wiggins (28) found a slight increase in tension produced by isolated ventricular strips, while Meijler (29) showed modest decreases in force development of Langendorff preparations. On the other hand, Whitehorn, Ullrick, and Anderson (30) demonstrated reductions in the maximum force developed by ventricular strips obtained from hyperthyroid rats stimulated at a frequency of $60 / \mathrm{min}$. This result can be accounted for by the finding of the present study, that as the frequency of contraction is increased in cardiac muscle from hyperthyroid animals, the rate of tension development increases proportionately less than the time to peak tension is abbreviated (Fig. 
5 ), and the net effect may be a variation in force development which does not parallel the changes in the contractile state of the myocardium, as reflected in $V_{\max }$.

Both temperature and frequency of contraction influence cardiac muscle obtained from hyperthyroid, euthyroid, and hypothyroid cats in similar manners, so that the differences observed among muscles obtained from the three groups of animals at any one temperature or frequency pertain to the entire range of temperature and frequency studied. It is of interest that variations of both temperature and frequency of contraction produce changes in heart muscle which are quite analogous to those induced by alterations in the thyroid state. As a consequence, when either the temperature or the frequency of contraction of hyperthyroid muscles is reduced, they behave like muscles obtained from hypothyroid animals. For example, the time to peak tension was essentially identical in muscles obtained from hyperthyroid cats studied at $21^{\circ} \mathrm{C}$, from euthyroid cats studied at $26^{\circ} \mathrm{C}$, and from hypothyroid cats studied at $28^{\circ} \mathrm{C}$. Similarly, the time to peak tension was approximately the same in muscles from hyperthyroid cats contracting at $6 / \mathrm{min}$, from euthyroid cats at $24 / \mathrm{min}$, and from hypothyroid cats at 48 ; min.

The manner in which patients with altered thyroid states respond to cardiac glycosides has long been of interest $(5,31,32)$. All workers who have examined the problem agree that both hypoand hyperthyroid heart muscle respond to the glycoside $(5,33-35)$; however, analysis of the problem in patients and intact experimental animals is complicated by the facts that the absorption and the turnover of the drug (36), as well as the fraction of the cardiac output which enters the coronary circulation $(37,38)$, may all be influenced by alterations in the thyroid state, making it diffcult to deliver a known concentration of drug to the myocardium. In an earlier study from this laboratory it was observed that the percentage increase in contractile force of the right ventricle of intact hyperthyroid dogs was only slightly, though not significantly, lower than that observed in euthyroid animals (33). In a similar preparation, Rosen and Moran noted no difference between euthyroid and hyperthyroid dogs in their inotropic response to moderate doses of ouabain, but found that larger doses caused a smaller inotropic response in hyperthyroid than in euthyroid animals (34). Peacock and Moran reported that hyperthyroidism diminished the contractile force developed by strips of the right ventricle of rats and reduced the increment in force after the addition of ouabain to the bath (35). The findings of the present investigation are, in general, not in accord with earlier studies, since we have observed that hyperthyroidism tends to augment the intrinsic tension development of the muscle and to reduce the response at every dose of strophanthidin.

Earlier investigators observed that hypothyroid dogs exhibited a normal increment of contractile force when ouabain was administered (34) and that the contractile force of right ventricular strips removed from hypothyroid rats, although greater than normal to begin with, showed reduced response after the addition of ouabain (35). The results of the present study are again not in concert with these findings, since we have noted that intrinsic contractile tension of muscles from hypothyroid cats tends to be reduced but that the increments of tension after the addition of strophanthidin were enhanced at every dose level studied. Our findings are, however, consistent with those obtained in an earlier study from this laboratory in which intact hypothyroid dogs were shown to exhibit a markedly increased inotropic response to infused ouabain (33).

An interesting finding of the present investigation was that the maximum increment in tension produced by strophanthidin varied reciprocally with the initial intrinsic isometric tension development, the muscles with the highest intrinsic contractility (the hyperthyroid group) exhibiting the smallest response to strophanthidin and the muscles with the lowest intrinsic contractility (the hypothyroid group) exhibiting the greatest response to strophanthidin. The average maximum tensions exhibited by all three groups of muscles after strophanthidin were almost identical and appeared to be independent of the thyroid state. Since the same contractile ceiling was reached by all three groups of muscles after strophanthidin, it appears that the increment in tension in response to the glycoside depends, at least in part, upon the degree to which the initial contractile state is altered by the level of thyroid activity.

It has been suspected for many years that an 
intimate relation exists between the sympathetic nervous system and the action of thyroid hormone (6). Alterations in cardiovascular function associated with hyperthyroidism resemble those produced by excess sympathetic influence and can be ameliorated by anti-adrenergic agents. Hence, these alterations have been considered to be mediated by catecholamines and not directly by thyroid hormone itself. In 1956, Brewster, Isaacs, Osgood, and King observed that the increased heart rate, oxygen consumption, cardiac index, and ventricular stroke work in hyperthyroid dogs could be abolished by epidural sympathetic blockade and then reproduced by norepinephrine infusion (39). They concluded that the hemodynamic changes of thyrotoxicosis result not from isolated activity of thyroid hormone but rather from the physiologic effects of catecholamines, particularly $l$-norepinephrine, as augmented by the thyroid hormones. Similarly, Lee, Morimoto, Bronsky, and Waldstein studied the peripheral manifestations of myxedema and thyrotoxicosis in patients and concluded that there was a synergistic relationship between thyroid hormone and the catecholamines (40). It has also been proposed that the effects on the heart of treatment with thyroxine are largely dependent upon the capacity of thyroxine to increase the catecholamine content of the heart (41). On the other hand, Van der Schoot and Moran (42) recently reported that hyperthyroidism does not potentiate, but tends to depress, the positive inotropic and chronotropic responses to catecholamines both in vivo (dogs) and in vitro (rat atria and ventricle strips); and Margolius and Gaffney found that pressor and chronotropic responses to endogenously released or exogenously administered norepinephrine in dogs were not affected by pretreatment with thyroid hormone or ${ }^{131} \mathrm{I}$ (43). Similarly, Wilson, Theilen, Hege, and Valenca showed that isoproterenol produced similar increments in heart rate and cardiac index in normal human subjects before and after triiodothyronineinduced hypermetabolism (44) and Wilson, Theilen, and Fletcher found that propranolol, in doses sufficient to block the effects of isoproterenol, did not alter the hemodynamic effects produced by triiodothyronine administration (45).

The present investigation permitted detailed analysis of the interactions of the thyroid state and the sympathetic nervous system on heart muscle. We observed that neither hyper- nor hypothyroidism resulted in significant changes in concentration of norepinephrine in the ventricle. This finding contrasts, on the one hand with that of Goodkind, Fram, and Roberts who found that myocardial norepinephrine concentration in guinea pig ventricles was increased by hyperthyroidism and decreased by hypothyroidism (46) ; and, on the other hand, with that of Kurland, Hammond, and Freedberg, who found that norepinephrine concentration in rabbit ventricles was decreased by hyperthyroidism and increased by hypothyroidism (47).

Of particular interest in the present study is the observation that the changes in the intrinsic contractile state of the myocardium induced by hyperthyroidism were not dependent on cardiac norepinephrine stores. Thus, similar increases in velocity of shortening and rate of tension development were noted in muscles from hyperthyroid animals with depleted, as well as with intact, norepinephrine stores (Fig. 8). Further, papillary muscles removed from hyperthyroid cats were not supersensitive to added norepinephrine but were actually quite subsensitive, whereas muscles removed from hypothyroid cats tended to respond somewhat more than did muscles removed from euthyroid cats. Therefore, the responses to added norepinephrine resemble those to strophanthidin in that the hyperthyroid muscles, exhibiting the highest level of contractile activity before addition of the inotropic agent, demonstrated the smallest increments in tension, while the muscles with the lowest level of intrinsic activity, i.e., those obtained from hypothyroid animals, showed the greatest responses. Thus, our findings indicate that thyroid activity modifies the intrinsic myocardial contractile state independently of norepinephrine. Although the effects on the heart of increased sympathetic activity resemble those of increased thyroid activity, the combined actions appear to be additive but not synergistic.

It was of interest to determine whether the induced alterations in contractile activity observed in the intact heart and the isolated papillary muscles of hyper- and hypothyroid animals were related to alterations in myocardial high energy phosphate stores. Previously no information was available concerning energy stores in hypothyroidism, and the effects of hyperthyroidism on high 
energy phosphate compounds were disputed. A number of investigators have reported marked depression of $\mathrm{CP}$ and ATP stores in the hearts of animals with hyperthyroidism (10-13). PiatnekLeunissen and Olson, on the other hand, have recently reported no significant differences in $\mathrm{CP}$ or ATP between the hearts of normal and hyperthyroid dogs (14). In the present study we observed that the concentrations of ATP, CP, and the sum of these two compounds in the euthyroid ventricles did not differ significantly from the concentrations of these substances observed in the hearts of either hyper- or hypothyroid cats. It is recognized that the concentrations of high energy phosphate compounds reflect the steadystate conditions existing in the myocardium rather than the turnover. However, the finding of normal values indicates, on the one hand, that the depressed contractile activity characteristic of the hypothyroid heart does not result from inadequate availability of energy, and, on the other hand, that the increased contractile activity characteristic of hyperthyroidism does not deplete available energy stores.

\section{Acknowledgments}

We gratefully acknowledge the skillful technical assistance of Nancy S. Dittemore and Shirley Seagren.

\section{References}

1. Resnik, W. H., and T. R. Harrison. 1966. The high-output and low-output syndrome. In Principles of Internal Medicine. T. R. Harrison, R. D. Adams, I. L. Bennett, W. H. Resnik, G. W. Thorn, and M. M. Wintrobe, editors. McGraw-Hill, New York. 788.

2. Howitt, G., and D. J. Rowlands. 1967. The heart in hyperthyroidism. Am. Heart J. 73: 282.

3. Theilen, E. O., and W. R. Wilson. 1967. Hemodynamic effects of peripheral vasoconstriction in normal and thyrotoxic subjects. J. Appl. Physiol. 22 : 207.

4. Ueda, H., Y. Sugishita, A. Nakanishi, I. Ito, H. Yasuda, M. Sugiura, Y. Takabatake, K. Ueda, T. Koide, and K. Ozeki. 1965. Clinical studies on the cardiac performance by means of transseptal left heart catheterization: II. Left ventricular function in high output heart diseases, especially in hyperthyroidism. Japan. Heart J. 6: 396.

5. Frye, R. L., and E. Braunwald. 1961. Studies on digitalis. III. The influences of triiodothyronine on digitalis requirements. Circulation. $23: 376$.

6. Harrison, T. S. 1964. Adrenal medullary and thyroid relationships. Physiol. Rev. 44, 161.
7. Hoch, F. L. 1962. Biochemical actions of thyroid hormones. Physiol. Rev. 42: 605.

8. Sonnenblick, E. H. 1962. Force-velocity relations in mammalian heart muscle. Am. J. Physiol. 202: 931.

9. Spann, J. F., Jr., E. H. Sonnenblick, T. Cooper, C. A. Chidsey, V. L. Willman, and E. Braunwald. 1966. Cardiac norepinephrine stores and the contractile state of heart muscle. Circulation Res. 19:317.

10. Mattonet, C. 1933. Chemischer Beitrag zur Frage der Herzmuskelschädigung durch Thyroxin. $Z$. Ges. Exptl. Med. 90: 237.

11. Berg, H. 1937. Uber den Herzmuskelstoffwechsel bei Hyperthyreose und seine Beeinflussung durch Vitamin C. Arch. Exptl. Pathol. Pharmakol. 185 : 359.

12. Schumann, H. 1939. Experimentelle Befunde zur Frage gesteigerter Thyroxinempfindlichkeit des mechanisch vermehrt belasteten Herzmuskels. $Z$. Ges. Exptl. Med. 105 : 577.

13. Holland, W. C., and R. L. Klein. 1960. Chemistry of Heart Failure. Charles C Thomas, Springfield. 116.

14. Piatnek-Leunissen, D., and R. E. Olson. 1967. Cardiac failure in the dog as a consequence of exogenous hyperthyroidism. Circulation Res. 20: 242 .

15. Furchgott, R. F., and T. De Gubareff. 1956. The determination of inorganic phosphate and creatine phosphate in tissue extracts. J. Biol. Chem. 223 : 377.

16. Pool, P. E., and E. H. Sonnenblick. 1967. The mechanochemistry of cardiac muscle. I. The isometric contraction. J. Gen. Physiol. 50: 951.

17. Bartorelli, C., and A. Gerola. 1963. Tidal volume, oxygen uptake, cardiac output, and body surface in the cat. Am. J. Physiol. 205: 588.

18. Spann, J. F., Jr., C. A. Chidsey, P. E. Pool, and E. Braunwald. 1965. Mechanism of norepinephrine depletion in experimental heart failure produced by aortic constriction in the guinea pig. Circulation Res. $17: 312$.

19. Fiske, C. H., and Y. Subbarow. 1929. Phosphocreatine. J. Biol. Chem. 81: 629.

20. Ennor, A. H., and H. Rosenberg. 1952. The determination and distribution of phosphocreatine in animal tissues. Biochem. J. 51:606.

21. Ennor, A. H. 1957. Determination and preparation of $\mathrm{N}$-phosphates of biological origin. In Methods in Enzymology. S. P. Colowick and N. O. Kaplan, editors. Academic Press Inc., New York. 3 : 850.

22. Strehler, B. L., and W. D. McElroy. 1957. Assay of adenosine triphosphate. In Methods in Enzymology. S. P. Colowick and N. O. Kaplan, editors. Academic Press Inc., New York. 3: 871.

23. Hill, A. V. 1938. The heat of shortening and the dynamic constants of muscle. Proc. Roy. Soc. (London), Ser. B. 126: 136. 
24. Csapo, A., and M. Goodall. 1954. Excitability, length-tension relation, and kinetics of uterine muscle contraction in relation to hormonal status. J. Physiol. (London). 126: 384.

25. Sonnenblick, E. H. 1967. Active state in heart muscle. Its delayed onset and modification by inotropic agents. J. Gen. Physiol. 50: 661.

26. Spann, J. F., Jr., R. A. Buccino, E. H. Sonnenblick, and E. Braunwald. 1967. The contractile state of cardiac muscle obtained from animals with experimentally produced ventricular hypertrophy and heart failure. Circulation Res. In press.

27. Buccino, R. A., J. W. Covell, E. H. Sonnenblick, and E. Braunwald. 1967. The effects of serotonin on the contractile state of the myocardium. $A m . J$. Physiol. In press.

28. Benforado, J. M., and L. L. Wiggins. 1965. Contractility, heart rate, and response to norepinephrine of isolated rat myocardium following $\mathrm{I}^{131}$-induced hypothyroidism. J. Pharmacol. Exptl. Therap. $147: 70$.

29. Meijler, F. L. 1963. Contractility of isolated hearts from myxedematous rats. Israel Med. J. 22: 395.

30. Whitehorn, W. V., W. C. Ullrick, and B. R. Anderson. 1959. Properties of hyperthyroid rat myocardium. Circulation Res. $7: 250$.

31. McIntosh, H. D., and J. J. Morris, Jr. 1965. Problems in the use of digitalis in the management of congestive heart failure. Progr. Cardiovascular Diseases. $7: 360$.

32. Rosenberg, M. S., and J. S. Graettinger. November 1962. Digitalis intoxication-management and prevention. Disease-A-Month. 1.

33. Morrow, D. H., T. E. Gaffney, and E. Braunwald. 1963. Studies on digitalis VII. Influence of hyper- and hypothyroidism on the myocardial response to ouabain. J. Pharmacol. Exptl. Therap. 140 : 324.

34. Rosen, A., and N. C. Moran. 1963. Comparison of the action of ouabain on the heart in hypothyroid, euthyroid, and hyperthyroid dogs. Circulation Res. 12: 479.

35. Peacock, W. F., and N. C. Moran. 1963. Influence of thyroid state on positive inotropic effect of ouabain on isolated rat ventricle strips. Proc. Soc. Exptl. Biol: Med. 113: 526.

36. Doherty, J. E., and W. H. Perkins. 1966. Digoxin metabolism in hypo- and hyperthyroidism. Ann. Internal Med. 64 : 489.
37. Rowe, G. G., J. H. Huston, A. B. Weinstein, H Tuchman, J. F. Brown, and C. W. Crumpton. 1956. The hemodynamics of thyrotoxicosis in man with special reference to coronary blood flow and myocardial oxygen metabolism. J. Clin. Invest. $35: 272$.

38. Bing, R. J. 1951. The coronary circulation in health and disease as studied by coronary sinus catheterization. Bull. N. Y. Acad. Med. $27: 407$.

39. Brewster, W. R., Jr., J. P. Isaacs, P. F. Osgood, and T. L. King. 1956. The hemodynamic and metabolic interrelationships in the activity of epinephrine, norepinephrine, and the thyroid hormones. Circulation. 13: 1 .

40. Lee, W. Y., P. K. Morimoto, D. Bronsky, and S. S. Waldstein. 1961. Studies of thyroid and sympathetic nervous system interrelationships. I. The blepharoptosis of myxedema. J. Clin. Endocrinol. Metab. 21 : 1402.

41. Lee, W. C., C. Y. Lee, and C. S. Yoo. 1965. Effects of treatment with thyroxine on the noradrenaline content of the rabbit heart. Brit. J. Pharmacol. 25: 651

42. Van der Schoot, J. B., and N. C. Moran. 1965. An experimental evaluation of the reputed influence of thyroxine on the cardiovascular effects of catecholamines. J. Pharmacol. Exptl. Therap. 149: 336.

43. Margolius, H. S., and T. E. Gaffney. 1965. The effects of injected norepinephrine and sympathetic nerve stimulation in hypothyroid and hyperthyroid dogs. J. Pharmacol. Exptl. Therap. 149: 329.

44. Wilson, W. R., E. O. Theilen, J. H. Hege, and M. R. Valenca. 1966. Effects of beta-adrenergic receptor blockade in normal subjects before, during, and after triiodothyronine-induced hypermetabolism. J. Clin. Invest. $45: 1159$.

45. Wilson, W. R., E. O. Theilen, and F. W. Fletcher. 1964. Pharmacodynamic effects of beta-adrenergic receptor blockade in patients with hyperthyroidism. J. Clin. Invest. 43 : 1697.

46. Goodkind, M. J., D. H. Fram, and M. Roberts. 1961. Effect of thyroid hormone on myocardial catecholamine content of the guinea pig. Am. J. Physiol. 201 : 1049.

47. Kurland, G. S., R. P. Hammond, and A. S. Freedberg. 1963. Relation of thyroid state to myocardial catecholamine concentration. Am. J. Physiol. 205 : 1270. 